Vol. 4, No. 1, 2017

https://doi.org/10.23939/eem2017.01.061

UDC 658: 005.3: 621 (477.8): 631.16

O. Kuzmin

Doctor of Economics, Professor

I. Prokopenko

$\mathrm{PhD}$ student

Lviv Polytechnic National University

\title{
MODEL OF ECONOMIC EVALUATION OF INTELLECTUAL CAPITAL OF MACHINE-BUILDING ENTERPRISES AND POTENTIAL OF THEIR DEVELOPMENT
}

\begin{abstract}
The article presents the results of building a model of economic evaluation of intellectual capital (IC) of machine-building enterprises suitable for the IC current level, its individual components and their potential. A typology of factors influencing the choice of IC evaluation methods in the industry has been developed. Factors of internal and external environment are described to consider when choosing a basic evaluation method of IC in machinebuilding enterprises, the direction and the impact of these factors in the current economic conditions in Ukraine being determined.The basic matrix selection method of evaluation of IC of machine-building enterprise, grounded priorities and a combination of different evaluation methods by defining their weighted grades are constructed. The graphical model of economic evaluation of machine-building enterprises IC and its development potential is designed. According to this model, indicators of the level of development of IC and its components in their cost measurement are calculated.
\end{abstract}

Keywords: intellectual capital, human capital, consumer capital, institutional capital, economic evaluation, development potential.

Formulation of the problem. A comparative analysis of the existing IC evaluation methods showed the possibility of their use in the practice of machine-building enterprises. However, it highlighted the problem of choosing a particular method of evaluation, its individual instruments and selection of indicators that would be convenient for the further IC regulation. To create a fundamentally new method of assessment for the purposes of regulating IC in machine-building enterprises is impractical as each individual organization has different strategic goals, environmental effects, market niche and contractors, so a standard approach will not work. In this case it is necessary to form a flexible assessment model that can be easily adapted to the needs of a particular company with the account of the changing external or internal IC parameters, which are to be formed.

Analysis of recent research and publications. The problem of estimating IC and its components (human, organizational and consumer capital) arises from the difficulty of obtaining relevant information. Most of the elements of these components are difficult for description using cost or quantity indicators, and it is difficult to unambiguously implement the proposed quality measuring devices into the system of monetary estimations. One of the first typologies of methods of IC evaluation was offered by K.-E. Sveiby, 2011 [1], David H. Luthy, 2006 [2], L. Edvinsson, 2000 [3]. In their publications after 1993-2011 they justified division of the IC evaluation methods into four groups: 1) Direct Intellectual Capital (DIC) methods; 2) Market Capitalization Methods (MCM); 3) Return on Assets (ROA) methods; 4) Scorecard (SC) Methods. Not all modern methods can be simply attributed to the mentioned groups, some of methods are intentionally created as a synthesis of monetary and quality descriptions, however, at present, this typology remains the most authoritative, though not the only one.The issues of evaluating IC and its components are dealt with in the works of D. Andriessen [4], E. Flemholts [5], B. Cuozzo, J. Dumay, M. Palmaccio, R. Lombardi [6] and many others.

Domestic researchers also discuss the methodology for evaluation of IC and its components, but unlike their western colleagues, they pay more attention to monetary evaluation of commercialized IC. In the works of A. Bosak [7] S. Illyashenko [8] O. Kendyukhov [9] O. Kuzmin [10], O. Melnyk [11], O. Mnykh [12] I. Moiseyenko [13], O. Shkurupiy [14] and others there are 
described the proven methods of IC evaluation and some of their modifications that have narrower application in machine-building enterprises of Ukraine. Most experts are inclined to believe that in conditions of weak stock market development it is best to use several methods of evaluating IC simultaneously, if the budget of the enterprise and the time frame for regulating the processes of IC formation and development allow to do this.

The least developed part of the methodology of economic evaluation of IC and its components is the study of internal and external factors that influence the choice of the basic method of evaluation and study groups using evaluation methods and their modifications, depending on the purpose of evaluation, resource constraints and performers' competence. It is necessary to develop a link between the IC evaluation method and regulatory actions on formation, development and commercialization of IC and its components.

The purpose of the research is to create a model of economic evaluation of IC of machinebuilding enterprises, which will keep track of the current state of IC, discover its reaction to regulatory actions, and assess the growth potential.
Consequently, we have to perform four interrelated tasks: 1) to identify the factors influencing the process of selecting basic methods of IC evaluation; 2) to establish a procedure for selecting components of IC evaluation methods according to the needs of the specific machine-building enterprises or groups; 3 ) to form a graphical model of economic evaluation of IC of machine-building enterprises and their development potential; 4) to calculate the basic indicators of evaluation of IC and its components on the basis of specific machinebuilding enterprises.

Materials and results. We divided all factors that affect the choice of the basic method of IC evaluation by several features, the impact environment being the main of them (Fig. 1). Other features have relatively less weight, though establishing the values of the weights of groups of factors depends on the objectives of IC evaluation and the structure of environmental influences. The choice of the evaluation method depends on a combination of factors that affect the enterprise at the moment and will do so in the future with a rather sufficient degree of probability.

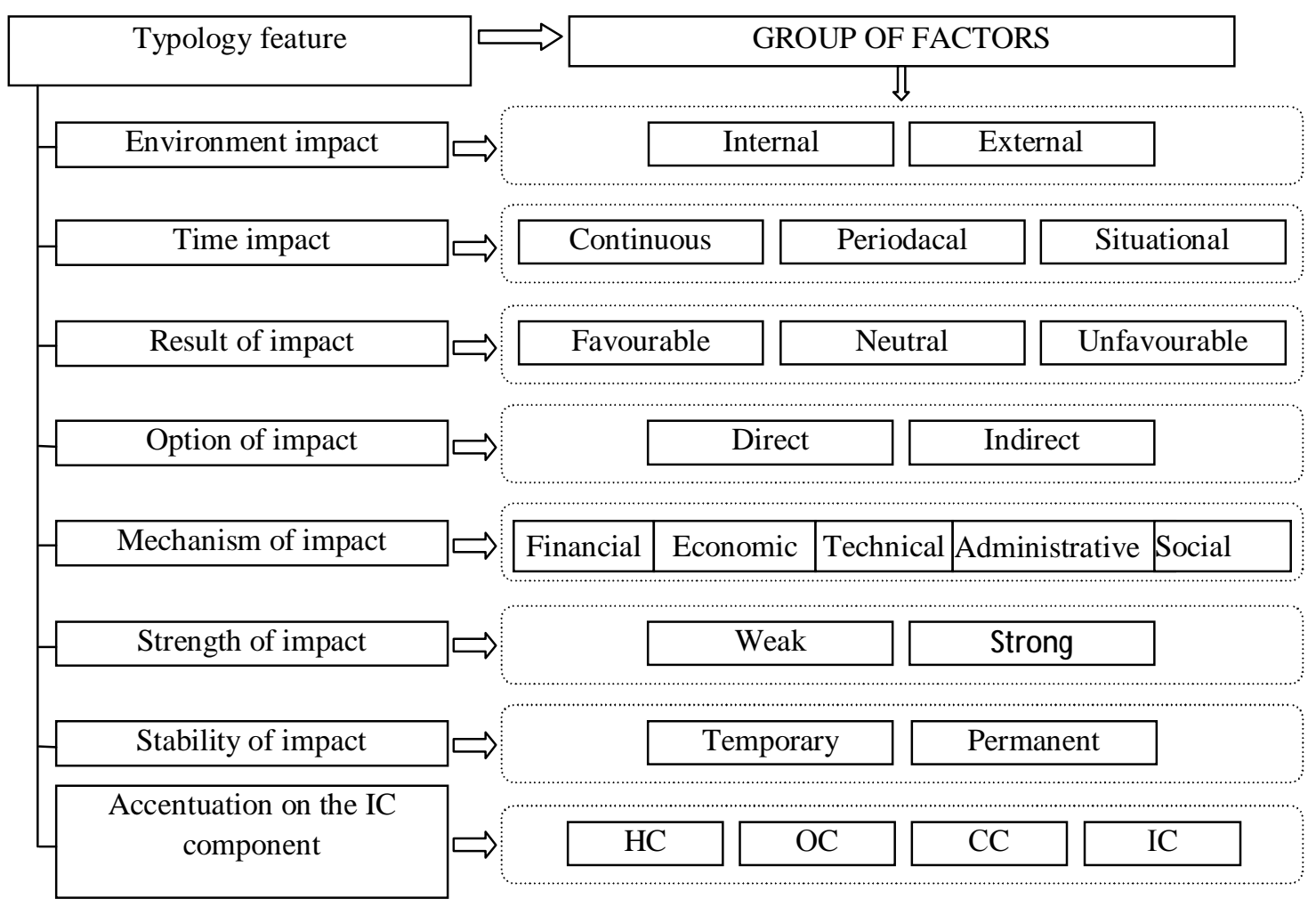

Fig. 1. A typology of factors influencing the choice of IC evaluation methods at machine-building enterprises

Note: developed by the author. 
If most of the factors have a continuous effect, you should implement a monitoring system of intangible assets (NMA) based on one of the famous DIC methods. Although DIC methods have problems with interpreting measuring instruments, when similar data are transmitted continuously and in real time, they will be a good base for comparison and making relevant administrative decisions regarding regulation of IC. Periodic and situational factors of impact give advantage to methods of evaluation from groups MCM or ROA because they provide an objective market characteristics of NMA, regardless of the time of measurement, its repeatability or data sampling.

If market factors have mostly favourable impact on the enterprise, there is enough time for choosing the methods of IC evaluation and any of them can be selected. If such impact is unfavourable, then, as the practice of Western corporations shows, the most effective evaluation methods are those from groups MCM or ROA, because they give quick and unambiguous monetary evaluation of the NMA, though they do not reflect the development potential of the individual IC components. There is actually no pure neutral impact of the environment on business; visible "neutrality" is usually the point of transition between the positive and negative influences, and therefore it is important not to be misled by its interpretation and, consequently, not to choose the wrong method of IC evaluation. Managers, who are professionally dealing with the objects of intellectual property (OİP) and NMA consider that the best situation for the company is permanent light adverse effect of the environmental factors, which stimulates well the intellectual activity of the personnel, but is not dangerous to the company's competitive position in the market.

If the factors of the external and internal environment affect the choice of IC evaluation method directly, they also give a hint about the method to be used for measuring the NMA, i.e. a direct effect itself chooses the method of measuring IC, as it programs the basic indicators for IC further regulation. If the influence is coming from consumers, there are suitable methods of evaluation of client and infrastructure capital based on SC tools; if it is coming from suppliers, the SC methods of measuring infrastructure capital within consumer and organizational capital are effective etc. It is worse with the indirect influence of the factors, because at the moment of action it is felt weakly, though its consequences can be odserved in different subsystems of the enterprise regardless of the point of application of this action. This means that it will be necessary to use all the groups of evaluation methods to find indicators that characterize the change in IC and its components as the result of these influences. If there is not enough time or money, it is recommended to use the simplest MCM-methods for corporations or ROA-methods for non-corporate forms.

The mechanism of impact of environmental factors on the procedure of selection and application of IC evaluation method appears in changing financial, economic, administrative, technological and social conditions of the enterprise functioning and development of its NMA. If the impacts are mainly financial and economic, the priority is given to the methods of assessing the monetary value of IC and its components. Otherwise, it can't be done without methods of SC and DIC groups.

The strength and stability of the factors of impact on the process of selecting and using the method of IC evaluation are more declarative in nature and affect such conditions of decision-making as time, management competence and the resources available at the moment. Strong and persistent negative impacts suggest the existence of threatening trends and probable problems of strategic character. In this situation the issue of IC regulation recedes to the background, though it is not so in case the enterprise specializes in producing innovative products with large share of expenditures on $R \& D$ and patent support. The company may feel a strong periodic pressure of the external environment in the process of commercializing its OIP and using patents and copyright. In this case, the methods of assessing the return on ownership of the patent rights and the value added obtained in the process of their use prevail. The problem is the identification of fastchanging factors that may be mediated and alleged to be weakly influenced, but their consequence may be the complete blockage of a single patent or even the initiation of litigation by competitors. In so doing, the purpose of litigation in the field of OIP or patent law is not so much the direct benefit of transferring the rights to a particular product, invention or technology, as the deterioration of reputation, and hence the market value of an opponent.

Often for the purposes of regulation of IC and its components there is needed information, concentrated around certain IC elements. Accentuation on the elements of the human, 


\section{O. Kuzmin, I. Prokopenko}

organizational or consumer capital limits the range of available methods of evaluation, as most of them give very approximate evaluation of the IC narrow segments. If you need an integrated IC evaluation, it is desirable to use two or three methods parallelly, and then output the weighted index of the IC development level. Unfortunately, in this case we lose the base for comparison with other enterprises, but sometimes it is of no importance.

As the environment is the initial feature of the typology of factors of impact that affect the choice of the IC evaluation method, it is the environment that also defines the criteria for selecting specific techniques and tools. Internal and external factors of impact are not homogeneous, therefore it is worth to explore them in more detail (Table 1). The strength of the impact factor indicates whether this factor will have priority in the process of choosing an IC evaluation method; the direction of impact shows whether the influence of this factor helps to choose appropriate methods of evaluation or, on the contrary, increases the level of uncertainty of the choice. Characteristics of the described factors of internal and external environment are the basis for constructing a matrix of the choice of the basic method of IC evaluation for machinebuilding enterprises (Table 2).

Factors of internal and external environment influencing the choice of the evaluation method of the IC and its components

\begin{tabular}{|c|c|c|c|}
\hline $\begin{array}{l}\text { Group of } \\
\text { factors }\end{array}$ & Factors & $\begin{array}{l}\text { The strength } \\
\text { of influence }\end{array}$ & $\begin{array}{c}\text { The } \\
\text { direction of } \\
\text { influence }\end{array}$ \\
\hline \multicolumn{4}{|c|}{ Internal environment } \\
\hline \multirow[t]{9}{*}{ Goals } & Inventory of IC, reports to the shareholders (owners) & + & 0 \\
\hline & Reengineering of business processes, launching new activities & + & + \\
\hline & $\begin{array}{l}\text { Preparation for the release of new products or the introduction of a new } \\
\text { technology }\end{array}$ & + & + \\
\hline & Finding ways of cost reduction & - & 0 \\
\hline & Preparation of proposals for investors & 0 & + \\
\hline & Preparation of a business plan to get a bank loan & - & 0 \\
\hline & Preparation for entering the international borrowing market & 0 & + \\
\hline & Preparation for placement of securities on the stock market & 0 & + \\
\hline & Reorganization, restructuring, sale of business or its part, merger & + & 0 \\
\hline \multirow[t]{5}{*}{ Personnel } & Qualifying characteristics, the system of retraining and advanced training & 0 & + \\
\hline & Age and gender structure, length of service, turnover, rotation & 0 & 0 \\
\hline & Intellectual activity, creativity & + & + \\
\hline & Satisfaction with payment and working conditions & 0 & 0 \\
\hline & Willingness to change, loyalty to the company, corporate culture & 0 & 0 \\
\hline \multirow[t]{4}{*}{ Structure } & Level of hierarchy, level of bureaucracy involved & 0 & - \\
\hline & Adaptability of the organizational management structure, delegation of authority & + & 0 \\
\hline & Level of development of communication system and document management & 0 & + \\
\hline & Level of elaboration of internal documents and regulations & 0 & + \\
\hline \multirow[t]{3}{*}{ Resources } & Provision of financial and material resources & + & + \\
\hline & Availability of time for decision-making & + & - \\
\hline & Level of development of information support & + & + \\
\hline \multicolumn{4}{|c|}{ External environment } \\
\hline \multirow{3}{*}{$\begin{array}{l}\text { Micro- } \\
\text { environment }\end{array}$} & Existing customers, suppliers, competitors, investors & + & 0 \\
\hline & Serving the banking, insurance, transport and other organizations & + & 0 \\
\hline & Local authorities & 0 & 0 \\
\hline \multirow{3}{*}{$\begin{array}{l}\text { Macro- } \\
\text { environment }\end{array}$} & Development potential of domestic market, level of competition & 0 & + \\
\hline & Consumer capability & - & - \\
\hline & Government authorities & - & 0 \\
\hline \multirow{3}{*}{$\begin{array}{l}\text { Global } \\
\text { environment }\end{array}$} & System of patent law & 0 & + \\
\hline & Level of development of technology & 0 & 0 \\
\hline & International environment and international developments & 0 & - \\
\hline
\end{tabular}

+ means strong (positive) influence; - is a sign of weak (negative) influence; 0 signifies neutral influence.

Note: generated by the authors. 
Model of Economic Evaluation of Intellectual Capital of Machine-building Enterprises...

Table 2

The matrix of choosing the basic IC evaluation method at a machine-building enterprise

\begin{tabular}{|c|c|c|c|c|c|c|c|c|c|}
\hline \multirow[t]{2}{*}{ Key factors } & \multirow{2}{*}{$\begin{array}{l}\text { Weight of } \\
\text { factors }\end{array}$} & \multicolumn{4}{|c|}{$\begin{array}{c}\text { Priorities of groups of } \\
\text { methods }\end{array}$} & \multicolumn{4}{|c|}{ Wieghed valuation } \\
\hline & & MCM & ROA & DIC & $\mathrm{SC}$ & MCM & ROA & DIC & $\mathrm{SC}$ \\
\hline 1 & 2 & 3 & 4 & 5 & 6 & 7 & 8 & 9 & 10 \\
\hline Monetary valuation of IC overall level & 0.12 & 3 & 2 & 1 & 0 & 0.36 & 0.24 & 0.12 & 0 \\
\hline Monetary valuation of IC components & 0.03 & 0 & 0 & 3 & 1 & 0 & 0 & 0.36 & 0.12 \\
\hline Qualitative assessment of IC overall level & 0.01 & 0 & 1 & 0 & 3 & 0 & 0.12 & 0 & 0.36 \\
\hline Qualitative assessment of IC components & 0.1 & 0 & 0 & 1 & 3 & 0 & 0 & 0.12 & 0.36 \\
\hline $\begin{array}{l}\text { Special requirements to the reliability of the } \\
\text { input data }\end{array}$ & 0.11 & 2 & 3 & 1 & 1 & 0.24 & 0.36 & 0.12 & 0.12 \\
\hline $\begin{array}{l}\text { Special requirements for the ease of } \\
\text { comparison }\end{array}$ & 0.06 & 3 & 3 & 2 & 1 & 0.36 & 0.36 & 0.24 & 0.12 \\
\hline $\begin{array}{l}\text { Possibility of use by non-enterprise } \\
\text { customers }\end{array}$ & 0.05 & 0 & 3 & 3 & 3 & 0 & 0.36 & 0.36 & 0.36 \\
\hline Necessity to consider market factors effects & 0.08 & 2 & 1 & 1 & 1 & 0.24 & 0.12 & 0.12 & 0.12 \\
\hline Time limit & 0.14 & 2 & 3 & 1 & 0 & 0.24 & 0.36 & 0.12 & 0 \\
\hline Limitations on financial resources & 0.05 & 3 & 3 & 1 & 1 & 0.36 & 0.36 & 0.12 & 0.12 \\
\hline Probability of staff resistance & 0.1 & 2 & 3 & 1 & 0 & 0.24 & 0.36 & 0.12 & 0 \\
\hline High level of red tape in the organization & 0.08 & 3 & 3 & 2 & 1 & 0.36 & 0.36 & \begin{tabular}{|l|}
0.24 \\
\end{tabular} & \begin{tabular}{|l|l|}
0.12 \\
\end{tabular} \\
\hline $\begin{array}{l}\text { Necessity of external presentation of the } \\
\text { results }\end{array}$ & 0.04 & 2 & 2 & 2 & 3 & 0.24 & 0.24 & 0.24 & 0.36 \\
\hline Need to maximize the market value & 0,03 & 3 & 2 & 1 & 1 & 0.36 & 0.24 & 0.12 & 0.12 \\
\hline Total & 1 & 25 & 29 & 20 & 19 & 3 & 3.48 & 2.4 & 2.28 \\
\hline
\end{tabular}

Note: generated by the authors.

The weight of the particular factors chosen for each company depends on the objectives of the IC evaluation, the needs of contractors and conditions of the external and internal environment. Traditionally, the sum of the weights of the factors is equal to the unit, however, in some cases this can be neglected. A combination of factors can also vary, although it is recommended to program their expanded set, and in case there is no need to consider this or that factor, it should just be assigned a 0 value as a weight coefficient. Each group of methods is assigned priority from " 0 " to " 3 ", and the better the group satisfies a specified condition, the higher its digital value of priority is.

The obtained integrated evaluation results are the basis for situational choice of the basic methods of IC evaluation. If there is a need (or desire to external contractors) to use simultaneously several groups of evaluation methods, they choose them by the next value of an integrated assessment. Then, within the selected groups, it is necessary to select a basic method of IC evaluation, and modify it to meet the needs of the enterprise by adding or removing individual indicators and/or procedures. The important stage of IC economic evaluation at a machine-building enterprise is the creation of the program and schedule of the IC internal audit, approved by the order of the company.

The model of IC economic evaluation at machine-building enterprises is built on the basis of the closed cycle of iterations of established criteria of sufficiency of the received information and the given accuracy of the evaluation results. Such a principle is convenient for further automation of work on calculations of the given indicators, presentation of results and their use in the process of IC regulation. The graphic interpretation of the model reflects the main stages of the IC economic evaluation and the procedures for its implementation in accordance with a combination of factors that affect the enterprise at a given stage of its life cycle (Fig. 2). 


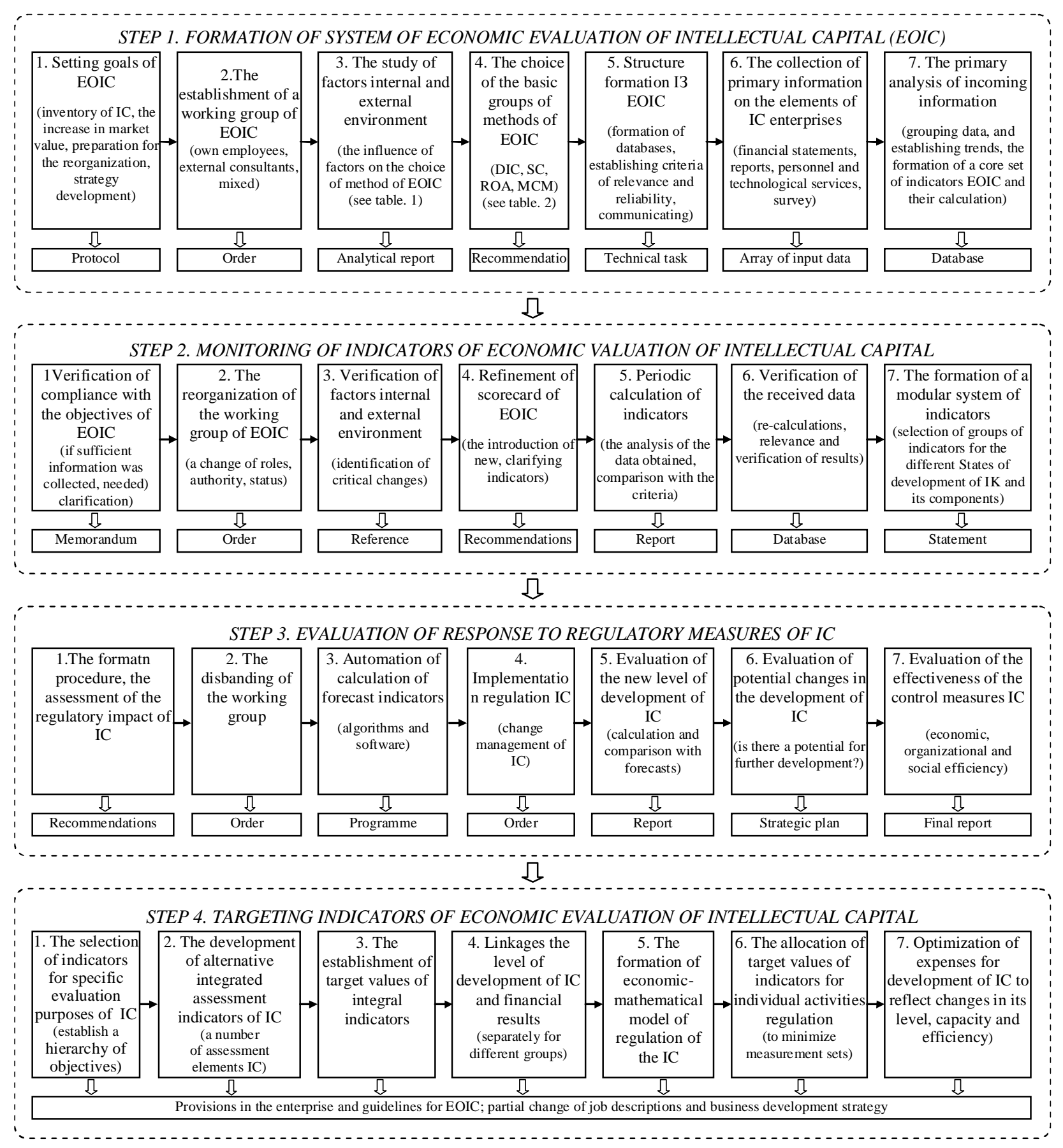

Fig. 2. Graphical model of economic evaluation

of IR machine-building enterprises and capacity development

Note: generated by the authors.

The first stage of the model involves the formation of the concept of the system of IC economic evaluation at the enterprise, which depends primarily on the goals that the management has set itself. These goals are of two levels: tactical (IC inventory, increase of market value of the enterprise, preparation for organizational changes) and strategic (planning of reorganization, system reengineering, designing a development plan). If the goal is one and it is clearly established, the formation of the EOIC system is relatively simple, it can often be limited to using one of the methods developed. However, in most cases, the management wants a universal and permanent EOIC system that would provide prompt answers to all questions that arise in 
connection with the development of the IC and its components and points to the results of the regulation of the IC. It is theoretically possible to create such a universal system, but it will be very cumbersome - it will have to constantly calculate and track many surplus indicators, therefore, in terms of the efficiency of the EOIC system and optimization of the time and money costs, it is still appropriate to limit it to partial sets of indicators. methods. It is unlikely that one and the same enterprise in the near future will reorganize its key business processes, will be subject to reorganization (merger, acquisition or sale), create and commercialize OIP, expand patent licensing activities etc.

Creation of a working group for formation of the EOIC system requires a detailed study of the organizational moments, because the functioning of this group can be quite long - up to full automation of monitoring and calculation of all necessary indicators and filling the corresponding database. The experience of big foreign industrial enterprises shows that mixed working groups, which will involve external consultants, and in some cases entire consulting group, working on a parity basis with the representatives of the major divisions of the company are most effective. The budget of such working groups is rather large, so in terms of domestic business the best format is as follows: one external consultant on a regular basis, several external experts of narrow profile and selected employees of the main production and functional units that collect and analyze primary information. It is clear that such a working group will be reorganized from time to time, and its main objective is to create an effective system of EOIC and implement it in the work of the enterprise. Western experience suggests that in the mediumsized enterprises, the processes of economic evaluation of IC and measures for its regulation can be completely automated, and control will be carried out by one of the functional units (mosty financial department). Large enterprises often have to allocate a sector in the functional services, or create a separate service, as they deal with all issues related to the development of the IC potential. There are many forms of organization: from the establishment of the position of the IC analyst to the allocation of several units dealing with integrated research and development of the IC (ranging from $\mathrm{R} \& \mathrm{D}$ and personnel to the commercialization of OIPs and its patent and licensing support).

Investigation of the factors of internal and external environment is the first step of the working group, the results of which allow to uniquely identify the basic group of EOIC methods. Subsequently, the members of the working group, with the support of unit managers, form the structure of the EOIC information support and collect the initial information about the elements of the enterprise IC. As a result of these works, a technical task for the creation of a database, modification of the existing system of communications and document circulation should be formed and approved by the management. Sources of obtaining primary information for EOIC are general financial statements of the enterprise, reports of individual units and data obtained from surveys of managers and leading specialists who are tangent to the formation of IC.

At this stage in the formation of the EOIC system, there exists the greatest probability of the emergence of a resistance of management and personnel, which will be manifested in reluctance to provide some data and become the subject of research. The problem is exacerbated by the fact that members of the working group or external experts involved will have to conduct numerous interviews and questionnaires in order to determine the intellectual potential of individuals and entire units. Part of the personnel will feel threatened with their further status at the enterprise (and not without reason) and therefore deliberately or unknowingly sabotage the initiatives of members of the working group. It will not be possible to completely eliminate this resistance by administrative methods, so some adjustments will have to be made to minimize the impact of critically-minded individuals and to conduct repeated and cross-polls to obtain reliable information.

The final result of the first stage of implementing the EOIC model at machine-building enterprises is the initial analysis of the input information, which consists in grouping the collected data, establishing trends in their changes and forming on their basis a basic set of EOIC 


\section{O. Kuzmin, I. Prokopenko}

indicators. These indicators are calculated over several available periods, and based on the results obtained, the database and the primary report are generated. This primary report will be limited to one period in terms of qualitative indicators, as they are obtained through direct communication with executives and leading specialists, and thus "retrospective" data can not be obtained. As for a full analysis it is necessary to have a comparative basis, only after passing through several subsequent periods (at least three one-quarterly polls) it can be argued that the data obtained are relevant and verified.

We should not forget that the very fact of the study of the level of development of IC and its individual components affects the managed subsystem as a regulatory measure. It is unlikely that someone will want to look less competent during the interview than they really are; there will be many attempts to "decorate" the reality or give the desired effect. A more sophisticated version of disinformation is possible: the respondents deliberately understate the current level of their competencies and development potential, in order to demonstrate "significant" growth next time.

The results of the survey of managers of machine-building enterprises indicate that most of those who recognize the expediency of investment in the development of IC, want to have a universal instrument of its assessment. Realizing that this universality does not allow to deeply explore the individual aspects of the IC components, they agree on the least labor-intensive sets of EOIC indicators, which will become peculiar markers of the direction of changing the IC potential And only after these indicators show a stable connection of investments in the IC development with the financial results of the enterprise, they consider it appropriate to modify the EOIC system in accordance with the objectives.

Based on the data obtained and the experience of Western industrial enterprises, we propose, at the first stage, to restrict the minimum number of IC evaluation indicators that are universal in relation to the purpose of evaluation. The calculation of the values of these indicators for a group of machine-building enterprises gives an idea of the general state of affairs in the field of IC development (Table 3). When identifying the objectives of the IC evaluation, these indicators can be supplemented by others that more accurately identify the causes and effects of changes in individual IC elements and components of the enterprise.

Table 3

The results of calculation of indicators of economic evaluation of IC and its components for the individual machine-building enterprise as of 1 January 2016

\begin{tabular}{|c|c|c|c|c|c|}
\hline \multirow[b]{2}{*}{$\begin{array}{c}\text { Indicators } \\
\text { (coefficients or ths UAH) }\end{array}$} & \multicolumn{5}{|c|}{ Values as of 1 January 2016} \\
\hline & $\begin{array}{l}\text { "Mayak" } \\
\text { PJSC, } \\
\text { Vinnitsa }\end{array}$ & $\begin{array}{c}\text { "Ukrelektro } \\
\text { aparat" } \\
\text { PJSC }\end{array}$ & $\begin{array}{l}\text { "Iskra" } \\
\text { PJSC }\end{array}$ & \begin{tabular}{|c|} 
"Lvivskyi \\
lokomotivorem \\
ontnyi zavod" \\
PJSC
\end{tabular} & $\begin{array}{c}\text { "Zavod } \\
\text { Elektron } \\
\text { pobutprylad" } \\
\text { LLC }\end{array}$ \\
\hline 1 & 2 & 3 & 4 & 5 & 6 \\
\hline \multicolumn{6}{|c|}{ TOTAL IC COST } \\
\hline Net income & 244270 & 501278 & 523538 & 284789 & 9587 \\
\hline Book value of assets & 128906 & 254073 & 662615 & 268404 & 44689 \\
\hline Market value of liquid assets & 142354 & 287658 & 801657 & 312840 & 73686 \\
\hline Turnover of liquid assets, \% & 171.6 & 174.3 & 65.3 & 91.0 & 13.0 \\
\hline Part of income, added by IC & 23076 & 58526 & 90804 & 40452 & 3773 \\
\hline Average interest rate on equity, $\%$ & 7 & 7 & 7 & 7 & 7 \\
\hline $\mathrm{IC}$ cost & 329655 & 836083 & 1297202 & 577880 & 53896 \\
\hline IC excess over book value of assets & 200749 & 582010 & 634587 & 309476 & 9207 \\
\hline Ratio of IC to book value of assets & 2.56 & 3.29 & 1.96 & 2.15 & 1.21 \\
\hline \multicolumn{6}{|c|}{ COST OF HUMAN CAPITAL (HC) } \\
\hline Number of employees & 790 & 924 & 1901 & 1380 & 128 \\
\hline Average productivity & 309.20 & 542.51 & 275.40 & 206.37 & 74.90 \\
\hline
\end{tabular}


Model of Economic Evaluation of Intellectual Capital of Machine-building Enterprises...

Continuation of the table 2

\begin{tabular}{|c|c|c|c|c|c|}
\hline 1 & 2 & 3 & 4 & 5 & 6 \\
\hline Average index of productivity growth & 1.1 & 1.13 & 1.17 & 1.13 & 1.19 \\
\hline Part of the income added by $\mathrm{HC}$ & 27141 & 74904 & 107230 & 42555 & 2249 \\
\hline $\mathrm{HC}$ cost & 193865 & 535025 & 765930 & 303962 & 16063 \\
\hline \multicolumn{6}{|c|}{ COST OF CONSUMER CAPITAL (CC) } \\
\hline Number of potential clients & 36 & 41 & 92 & 14 & 21 \\
\hline $\begin{array}{l}\text { Average amount of the order of the regular } \\
\text { customer }\end{array}$ & 216.5 & 311.3 & 168.7 & 845.9 & 29.3 \\
\hline Average order of a regular customer & 18.3 & 23.4 & 6.3 & 23.7 & 3.5 \\
\hline Part of the income, added by CC & 7135.2 & 11803.9 & 14940.8 & 11510.8 & 541.8 \\
\hline $\mathrm{CC}$ cost & 50966 & 84314 & 106720 & 82220 & 3870 \\
\hline \multicolumn{6}{|c|}{ COST OF ORGANISATIONAL CAPITAL (OC) } \\
\hline Residual value of OC & 84825 & 216744 & 424552 & 191698 & 33963 \\
\hline \multicolumn{6}{|c|}{ STRUCTURE OF IC } \\
\hline Share of $\mathrm{HC}, \%$ & 58.81 & 63.99 & 59.04 & 52.60 & 29.80 \\
\hline Share of CC, \% & 15.46 & 10.08 & 8.23 & 14.23 & 7.18 \\
\hline Share of OC , \% & 25.73 & 25.92 & 32.73 & 33.17 & 63.02 \\
\hline
\end{tabular}

Note: the author collected the data groups of the indicators and calculated their values

The IC monetary evaluation is always subjective, because it is based on the value of assets that are not fixed in the form, and the potential for their transformation into the enterprise's revenue is probabilistic. In an advanced stock market, it is simpler to determine the value of an IC as the difference between the market value of its shares and the book value of assets. But in Ukraine the stock market is not developed, therefore, it is necessary to look for other ways of estimating the monetary value of IC. As guidelines, we can take into account the liquidation value of assets, the forecast of profits for a long period of operation of the enterprise, mortgage value of the property, market value of raw materials and materials, land plots, buildings etc.

Having studied the work of scientists and practitioners [1-15], we believe that in the first approximation, the cost of an IC can be determined by taking into account the income added by intellectual assets and the average interest rate on equity as a discount factor. We proceed from the fact that the cost of IC is formed over a long period of time, reversed to this ratio:

$$
\mathrm{I} C=\frac{D_{\mathrm{I} C}}{\overline{\mathrm{C}_{\mathrm{AC}}} / 100}
$$

where $D_{\text {IC }}$ - part of the income added by IC; thousand $\mathrm{UAH} ; \overline{\mathrm{C}_{\mathrm{AC}}}-$ the average share rate; $\%$.
Since we cannot directly determine the value of the average interest rate on equity, as most domestic enterprises do not pay real dividends, we assume that $\overline{\mathrm{C}_{\mathrm{AC}}}=0,5 * \mathrm{O}_{\mathrm{NBU}}$, where $\mathrm{O}_{\mathrm{NBU}}$ is the NBU discount rate, which at the time of our calculations was $14 \%$.

Part of the income added by the IC is determined by the formula:

$$
D_{\mathrm{I} C}=D_{I}-B_{\Sigma} \times \frac{0_{\mathrm{A}}^{L}}{100},
$$

where $D_{I}-$ net income of the enterprise; thousand $\mathrm{UAH} ; \mathrm{B}_{\Sigma}-$ book value of assets; thousand $\mathrm{UAH}$; $\mathrm{O}_{\mathrm{A}}^{L}$ - the turnover of liquid assets, $\%$.

In its turn, the turnover of liquid assets is calculated in the following way:

$$
\mathrm{O}_{\mathrm{A}}^{L}=\frac{D_{r}}{\overline{\mathrm{A}_{L}}}
$$

where $D_{r}$ - income of the enterprise from sales; thousand UAH; $\overline{\mathrm{A}_{L}}-$ average annual cost of liquid assets; thousand $\mathrm{UAH}$.

If an enterprise really works, then the growth rate of its income exceeds the growth rate of its tangible assets. However, in the structure of tangible assets there is a part of illiquid assets or those that do not participate in the production process. Using formulas (2-3), we separate that part of the enterprise's income, which is not explained by the use of tangible assets and we 


\section{O. Kuzmin, I. Prokopenko}

consider it the equivalent of IC in cash. Since this capital is used for a long time and generates relevant revenues, we discount it at a rate or at the level of the average share of equity or at half the NBU discount rate.

The calculations made for five companies (see Table 3) show that the value of their IC exceeds the book value of assets by half on average. This is the expected result, since the market value of the assets of enterprises is predominantly higher than the non-indexed balance sheet and, moreover, contains a component brought in by intangible assets that participate in the production but not are reflected in the balance sheet. The higher the ratio of IC to the book value of assets, the higher the probability that the company has a high potential for development.

Conditional value of IC is the sum of the value of human, consumer and organizational capital of the enterprise. The conditionality of an algebraic sum consists in the fact that the cost of IC is formed over a long period of time, and its commercialization is prepared for years, although it may be realized (converted into money) at a moment, if the enterprise is sold. In addition, the object of sale is the whole enterprise, and the IC only increases its value. However, at the same time, we will definitely wonder what part of the value of the IC is formed at the expense of human resources and their potential, which at the expense of customers, and what part of value is formed at the expense of the system and technology of business management. New owners of the company will implement its partial reorganization and the answers to these questions determine the strategy of their behavior in the purchase and development of business, business process reengineering, integration with other business entities and much more.The simplest, but fairly accurate measure of the cost of human capital of an enterprise is the determination of part of its income, which is added by the intellectual potential of the staff:

$$
D_{H C}=D_{I} *\left(1+\sum_{\mathrm{i}=1}^{n}\left(\mathrm{I}_{P G}-1\right)^{i}\right)-D_{I},
$$

where $D_{I}-$ net income of the company; thousand $\mathrm{UAH} ; \mathrm{I}_{\mathrm{PG}}-$ the index of productivity growth; $n-$ the number of periods during which human capital is formed.

$$
\mathrm{I}_{P G}=\frac{P G_{1}}{P G_{0}}
$$

where $\mathrm{PG}_{0}, \mathrm{PG}_{1}$ - labour productivity in the base and fiscal periods, respectively; thousand UAH/person;

$$
P G_{0(1)}=\frac{D_{I}}{N_{A}}
$$

where $D_{I}-$ net income of the enterprise; thousand $\mathrm{UAH} ; N_{A}-$ the average number of employees; persons

$$
n=\frac{1}{r}
$$

where $r$ - the discount factor (in our case corresponds to the discount rate of the NBU, it being 0.14 ).

Taking into account (5-7), the modified formula for calculating the income added by human capital will look like this:

$$
\begin{aligned}
\mathrm{D}_{\mathrm{HC}}= & D_{I} *\left(\mathrm{I}_{P G}+\left(\mathrm{I}_{P G}-1\right)^{2}+\right. \\
& \left.+\cdots+\left(\mathrm{I}_{P G}-1\right)^{7}-1\right),
\end{aligned}
$$

Then the value of human capital will be:

$$
H C=\frac{D_{H C}}{r},
$$

where $\mathrm{D}_{\mathrm{HC}}$ - income added by human capital; thousand UAH; $r$ - discount rate (NBU discount rate, $r=0.14$ ).

Similarly, we calculate the value of consumer capital of enterprises, but here the main indicator will be the number of regular customers and its average order volume, since these are the customers that generate long-term revenue growth. The share of income created by client capital is calculated as follows:

$$
D_{C C}=\left(\overline{Z_{f l x}}-\bar{Z}_{\imath}\right) \times N_{f i x},
$$

where $Z_{f i x}, Z_{l}$ - average size of purchases by regular and ordinary consumers; thousand UAH; $N_{f i x}$ - the number of regular consumers; persons.

The average size of the purchase of a regular customer is:

$$
\overline{Z_{f l x}}=\frac{\sum_{i=1}^{N_{f i x}} Z_{f i x_{i}}}{N_{f i x}},
$$

where $Z_{f i x_{1}}$ - the volume of purchases of the $i$-th regular customer; thousand UAH; $N_{f i x}-$ the number of regular customers. 


\section{Model of Economic Evaluation of Intellectual Capital of Machine-building Enterprises...}

Then the volume of consumer capital will be:

$$
\mathrm{CC}=\frac{D_{\mathrm{CC}}}{r}
$$

where $\mathrm{D}_{\mathrm{CC}}$ - income added by human capital; thousand UAH; $r$ - the discount rate (NBU discount rate, $r=0.14$ ).

The cost of organisational capital is hard to calculate, so we will proceed from the assumption that:

$$
\mathrm{IC}=\mathrm{HC}+\mathrm{CC}+\mathrm{OC},
$$

where $\mathrm{HC}, \mathrm{CC}, \mathrm{OC}-$ the cost of human, consumer and organizational capital of the enterprise, respectively, at a fixed time; thousand UAH.

The results of the calculation of these indicators for five enterprises (see Table 3) indicate that the basis of IC is human capital (an average of $52.85 \%$ ), while the smallest share (on average $11.04 \%$ ) is generated by consumer capital. This is typical for machine building industry, because the main buyers are allied companies that have collaborated for a long tim; the market is not dynamic, so work with customers is not very important. More important is the production technology and technical characteristics of the finished product, which, together with the management system, form the organizational capital.

Conclusions. The developed model of economic evaluation of IC of machine-building enterprises and their development potential is based on the identification of factors of influence on the process of choosing the basic methods of estimating IC and the formation of a procedure for selecting components of methods for estimating IC in accordance with the needs of specific machinebuilding enterprises or their groups. Accordingly, a typology of factors of influence on the choice of methods for evaluating IC of machine-building enterprises and a matrix of choice of the basic method for evaluating IC have been developed, integrated estimates for the situational choice of the base group of methods for evaluating IC are derived. The graphic model of the economic evaluation of the IC of machine-building enterprises and the potential for its development consists of four parts: the formation of the system of economic evaluation of the IC (EOIC), the monitoring of the EOIC indicators, the evaluation of the response to the measures of regulation of the
IC, the targeting of EOIC indicators. The first two parts reflect the concept of EOIC, the selection of relevant indicators, their monitoring and appropriate organizational support. The last two parts are designed to form a mechanism for regulating the IC, based on the constant tracking of changes in key parameters of the IC and its components and the elimination of deviations.

The developed system of indicators EOIC covers the quantitative and qualitative indicators of IC as a whole and its components: human, organizational and consumer capital. For five machine-building enterprises, monetary indicators were calculated on the basis of the proposed methodology for determining the proportion of income derived from the use of human and consumer capital. The cash equivalent of organizational capital is proposed to be determined as a residual value, and the total level of IC - as the value added by intangible assets and discounted at the average rate of the equity capital or its substitute.

The proposed method for calculating the monetary equivalent of IC and its components can be used for any machine-building enterprise, but then for each enterprise it is necessary to form their own system of indicators by choosing from the array of proposed indicators for calculation. The criteria for choosing the indicators for assessing the IC should be: the optimal combination of formalization of calculation and adaptability to application in the practice of the enterprise; symmetric mapping of various components of the IC and their individual elements; a combination of quantitative (physical and monetary) and qualitative indicators and the possibility of bringing them to a common basis; minimizing the number of duplicate indicators and eliminating the impact of sharp onetime changes in input data; suitability for repeated calculation in short and long periods of time within the limits of IC regulation. Actually, the development of an economic and mathematical model for optimizing the indicators of evaluation and minimizing their deviations from the planned values as a result of regulation of the IC is a further direction of our study.

\section{References}

1. Sveiby, K.-E. (accessed 11 November 2011). Methods for Measuring Intangibles Assets. 


\section{O. Kuzmin, I. Prokopenko}

Retrieved from http://www.sveiby.com/articles/ IntangibleMethods.htm

2. Luthy, D. (2006). Intellectual capital and its measurement. Logan, Utah. College of Business Utah State University, 18.

3. Edvinsson, L. (2000). Some perspectives on intangibles and intellectual capital. Journal of Intellectual Capital, 1, (1), 12-16.

4. Andriessen, D. (2007).IC valuation and measurement: Classifying the state of the art. Journal of Intellectual Capital, 5, (2), 230-242.

5. Flamholtz, E. (2012). Human Resource Accounting: Advances in Concepts, Methods and Applications. Springer Science \& Business Media, 390.

6. Cuozzo, B., Dumay J., Palmaccio, M. \& Lombardi, $R$. (2017). Intellectual capital disclosure: a structured literature review. Journal of Intellectual Capital, 18, (1), 9-28.

7. Bosak, A. O. \& Trevogo, O. I. (2015). Economic evaluation and the development of communications in the management system of intellectual capital of the enterprise. Lviv: ST "City Information System", 326.
8. Illiashenko, S. M. (2009). The methodical approach to the valuation of intellectual capital region. Mechanism of Economic Regulation, 1, 138-141.

9. Kendiukhov, O. V. (2008). Effective management of intellectual capital. NAS, Ukraine, Economy and Industry Institute, Donetsk: DonUEP, 363.

10. Kuzmin, O. Yev. \& Georgiadi, N. G. (2006). The formation and use of the information system management of economic development of the enterprises. Lviv: Publishing House of the National University "Lviv Polytechnik", 368.

11. Melnyk, O. G. (2010). Diagnostics of activity of engineering enterprises : polchatelya concept and tools: polchatelya concept and tools. Lviv: Publishing House of the National University "Lviv Polytechnik”, 344.

12. Mnykh, O. V. Marketing in the Formation of the market value of the machine-building enterprise: theory and practice. Lviv: Publishing House of the National University "Lviv Polytechnik", 428.

13. Moiseenko, I. P. (2007). Managing intellectual potential. L.: Avers, 303.

14. Shkurupiyi, O. V. (2009). Intellectual capital in social reproduction. K.: KNEU, 33. 